\title{
Familial appendiceal tumours in Diffuse Peritoneal Adenomucinosis and peritoneal mucinous carcinomatosis: A rare familial predisposition?
}

\author{
Samuel J. Davies*1, Mathew Doyle ${ }^{2}$, Sonia Tran ${ }^{3}$, Helen Kennedy ${ }^{4}$, David L. Morris ${ }^{5}$ \\ ${ }^{1}$ Department of Surgery, St George Hospital, Kogarah, NSW, Australia \\ ${ }^{2}$ Graduate School of Medicine, University of Wollongong, Wollongong, NSW, Australia \\ ${ }^{3}$ School of Medicine, University of Sydney, NSW, Australia \\ ${ }^{4}$ School of Medicine, University of New South Wales, Sydney, NSW, Australia \\ ${ }^{5}$ Department of Surgery, University of New South Wales, St George Hospital, Kogarah, NSW, Australia
}

Received: April 30, 2016

DOI: $10.5430 /$ css.v3n1p6
Accepted: October 31, 2016

URL: http://dx.doi.org/10.5430/css.v3n1p6

\begin{abstract}
Epithelial neoplasms of the appendix are rare. They account for an annual age adjusted incidence of 4 cases per 1,000,000. The low incidence of primary appendix tumours means that there are very few published reports of the familial occurrence. This case series reports two cases of primary appendiceal epithelial tumours in two sets of relatives. A genetic evaluation was performed to determine if there was any underlying single gene disorder, which could account for the familial occurrence. The results showed there was no DNA mismatch repair defect evident. This means that the occurrence of appendiceal cancer in siblings may represent a random event. However, exceedingly rare predisposition syndrome cannot be ruled out from our analysis.
\end{abstract}

Key Words: Familial appendiceal cancer, Pseudomyxoma peritonei, Diffuse Peritoneal Adenomucinosis, Epithelial neoplasms, Hyperthermic intraperitoneal chemotherapy

\section{INTRODUCTION}

Epithelial neoplasms of the appendix are rare with an annual age-adjusted incidence of 4 cases per 1,000,000. ${ }^{[1]}$ These tumours are often diagnosed incidentally during surgery - either for acute appendicitis or exploration of other abdominal symptoms. The majority of appendiceal epithelial cancers are of mucinous histological subtype. ${ }^{[2,3]}$ They are classified according to the degree of cellular atypia and the architecture of the epithelial cells. ${ }^{[3]}$ Pseudomyxoma peritonei (PMP) is a clinical entity whereby abdominal symptoms are produced from seeding of appendiceal tumours into the abdominal cav- ity and/or infiltration into local organs. ${ }^{[4]}$ Low-grade PMP describes well-differentiated disease from epithelial origin. Peritoneal deposits of these low-grade tumours are often insidious in evolution, and once seeded into the abdomen, are termed Diffuse Peritoneal Adenomucinosis (DPAM). ${ }^{[3]}$ High-grade appendiceal cancer with peritoneal disease is referred to as Peritoneal Mucinous Carcinomatosis (PMCA).

Low overall incidence of primary appendiceal tumours permits only a few published reports of epithelial appendiceal cancers occurring within the same family. This report describes two cases of primary appendiceal tumours in two sets

*Correspondence: Samuel J. Davies; Email: samuel.davies1@ gmail.com; Address: Department of Surgery, St George Hospital, Kogarah, NSW, 2217, Australia. 
of relatives from a single centre, and reflects on our experience with appendiceal cancers at a specialised centre. We look at surveillance of these patients and discuss whether screening of family members could be beneficial.

\section{Case representation}

\subsection{Case 1}

Patient A: A 65-year-old male initially presented to his local doctor with upper abdominal discomfort. Physical examination revealed a firm upper abdominal mass and CT imaging identified omental caking and ascites. Gastroscopy and colonoscopy did not identify any malignant features. Diagnostic laparoscopy showed PMP predominantly affecting the upper abdomen and straw-colored ascites. Histology revealed neoplastic glands and mucin consistent with mucinous adenocarcinoma. He was then referred to our unit for cytoreductive surgery during which an appendiceal primary tumor was identified. He received hyperthermic intraperi- toneal chemotherapy (Mitomycin C 41.5 degrees Celsius) for 90 minutes. Histopathology identified a well-differentiated mucinous adenocarcinoma.

Patient B: A 60-year-old brother of Patient A presented to his local doctor after non-specific right-sided abdominal discomfort, approximately 12 months after his elder brother's definitive cytoreductive surgery. No personal history of cancer or other significant medical history was identified. A CA-19.9 was ordered in light of the above-mentioned history of his brother, which returned an elevated result. Abdominal ultrasound subsequently identified a lesion in close proximity to the appendix, and CT imaging revealed a hypodense lesion in the right paracolic gutter behind the caecum. He underwent open appendectomy and the lesion was excised. Histopathology revealed a low-grade appendiceal mucinous neoplasm in a dilated appendix with no defect in the appendiceal wall and no local serosal surface involvement. Tumour markers are included in Table 1.

Table 1. Patient \& tumour characteristics + tumour markers

\begin{tabular}{|c|c|c|c|c|}
\hline Patient & $\bar{A}$ & $\mathbf{B}$ & $\mathrm{C}$ & $\bar{D}$ \\
\hline Age & 65 & 60 & 50 & 60 \\
\hline Sex & M & M & $\mathrm{F}$ & M \\
\hline Pathology & $\begin{array}{l}\text { DPAM } \\
\text { (Well-differentiated } \\
\text { mucinous } \\
\text { adenocarcinoma) }\end{array}$ & $\begin{array}{l}\text { Low grade appendiceal } \\
\text { mucinous neoplasm } \\
\text { confined to appendix - no } \\
\text { rupture }\end{array}$ & $\begin{array}{l}\text { PMCA } \\
\text { (Poorly-differentiated } \\
\text { mucinous } \\
\text { adenocarcinoma with } \\
\text { signet cells) }\end{array}$ & $\begin{array}{l}\text { DPAM } \\
\text { (Well-differentiated } \\
\text { mucinous } \\
\text { adenocarcinoma) }\end{array}$ \\
\hline Surgery & CRS + HIPEC & Open appendicectomy & $\begin{array}{l}\text { CRS + HIPEC + EPIC } \\
\text { (abandoned) }\end{array}$ & Right-hemicolectomy \\
\hline $\begin{array}{l}\text { CEA } \\
\text { (ref: }<2.5 \mathrm{ng} / \mathrm{ml})\end{array}$ & 40 & 2.9 & 4 & 1 \\
\hline $\begin{array}{l}\text { Ca } 19.9 \\
\text { (ref: }<40 \mathrm{kU} / \mathrm{ml} \text { ) }\end{array}$ & 282 & 32 & 24 & 38 \\
\hline $\begin{array}{l}\text { Ca } 125 \\
\text { (ref: }<35 \mathrm{kU} / \mathrm{ml} \text { ) }\end{array}$ & $\mathrm{n} / \mathrm{a}$ & 19 & 200 & 6 \\
\hline
\end{tabular}

Note. DPAM: Diffuse Peritoneal Adenomucinosis; PMCA: Peritoneal Mucinous Carcinomatosis; HIPEC: Hyperthermic Intraperitoneal chemotherapy; EPIC: Early Postoperative Intraperitoneal Chemotherapy ; CRS: Colorectal Surgery; CEA: Carcinoembryonic Antigen

Follow up CT imaging did not identify any features of PMP or any other metastatic foci. He continues to have annual tumour markers and abdominal CT imaging as surveillance and has had no further abnormalities identified.

\subsection{Case 2}

Patient C: A 50-year-old female was initially referred for gynaecologic opinion following investigation of her ill-defined abdominal-pelvic pain. Examination was consistent with a fixed mass arising from the pelvis and pelvic ultrasound diagnosed a large uterine fibroid. She had previously under- gone gastroscopy, colonoscopy and cervical Pap smear that did not identify any malignant or pre-cancerous lesions. Exploratory laparotomy identified an infiltrating tumour mass thought to be arising from her ovary, with disseminated intraperitoneal spread. A debulking procedure was performed and histology revealed metastatic, poorly differentiated mucinous adenocarcinoma with signet ring cells. She then underwent cytoreductive surgery that revealed a $2 \mathrm{~cm}$ firm mass at the terminal ileum identified as the primary tumour. She received HIPEC (Mitomycin C 41.5 degrees Celsius) for 90 minutes and began her post-operative course of EPIC (early postoper- 
ative intraperitoneal chemotherapy), which was abandoned due to abdominal compartment syndrome. Histopathology confirmed disseminated invasive moderately to poorly differentiated adenocarcinoma, predominantly signet ring type.

Patient D: A 60-year-old male who is the first cousin of $\mathrm{Pa}$ tient $\mathrm{C}$ underwent a routine medical check required by his employer, identifying glycosuria. Pancreatic imaging was sought and he ultimately underwent an abdominal-pelvic CT scan that identified a distended appendix with a small fluid-filled collection in close proximity. Laparoscopy identified an invasive appendiceal tumour with focal rupture and mucinous deposits over the surface of the caecum. A right hemi-colectomy was performed and histopathology identified a well-differentiated mucinous adenocarcinoma. No further disease has been identified on follow up.

\section{Discussion}

Primary epithelial appendiceal tumours are relatively rare, accounting for only $1 \%$ of all colorectal cancers. ${ }^{[4]}$ For most patients, identification of these tumours occurs intraoperatively, with approximately $1 \%$ of acute appendicectomy specimens found to have appendix cancers within them. ${ }^{[3]}$ There are no clear inheritance patterns explaining the familial recurrence of these uncommon cancers that have been identified previously. Some authors however have suggested that familial predisposition may be possible. ${ }^{[2]}$

According to our literature search, 3 other familial cases of primary appendiceal tumours exist in the current published literature, with only a single case report of appendiceal adenocarcinoma in two first-degree relatives. ${ }^{[2,5,6]}$ Inheritance patterns explaining the familial recurrence of these uncommon cancers have not previously been identified, although some authors suggest that familial predisposition may be possible. ${ }^{[2]}$

Classification and diagnosis of appendiceal mucinous tumours has been controversial for several decades and the molecular basis of mucinous tumours remains unclear. ${ }^{[7,8]} \mathrm{It}$ is known that most colorectal cancers develop from adenomatous polyps, and morphological and genetic progression in an adenoma-adenocarcinoma sequence and in hereditary colorectal cancer syndromes are well described. Previous studies into the genetic alterations in appendiceal carcinoma has shown that it is distinct from colorectal cancer. ${ }^{[9]}$ The molecular basis for the development of appendiceal mucinous tumours remains unclear. It has been shown that KRAS is frequently mutated in the majority of low-grade appendiceal neoplasms and mucinous adenocarcinomas, whereas GNAS mutation is only observed in of low-grade appendiceal neoplasms. ${ }^{[10]}$ Overexpression of $\mathrm{p} 53$ is reported to be 8 rare in appendiceal tumours and, although KRAS mutation and p53 overexpression can be seen in half of PMP cases of appendiceal origin. ${ }^{[11]}$

Microsatellite instability has also been shown to be rare in appendiceal carcinoma, and hyper-methylation is not a mechanism for genetic instability in these tumours although some hyperplastic polyps and sessile serrated adenomas of the appendix show decreased expression of MLH1 and BRAF mutation is more common in serrated polyps. ${ }^{[7]}$

The only consistent risk factor identified for appendiceal cancer is increasing age. There has been no evidence of any other risk factors. Often with cancer however there is a strong family history. A detailed family history of cancers for both cases presented was performed. Case 1 revealed that patient A and B father had metastatic prostate cancer, as well as another sister had melanoma. There was no history of bowel cancer in either parent or other sibling was identified. Case 2 showed a cousin diagnosed with peritoneal involvement of their primary appendiceal tumours, with no first-degree relatives having any history of cancer.

Advising about screening of unaffected family members is difficult. Advice about potential screening for these tumours in other asymptomatic family members was sought from each of the families in our cases. We attempt to provide some recommendations based on the current literature and the experience at our centre. Our centre has performed over 670 peritonectomy procedures, 101 of which being for primary appendix tumours. No other familial instances were identified from our centre.

As no risk factors except for increasing age, have been identified for primary mucinous tumours originating from appendiceal epithelium. There are reports of patients with inflammatory bowel disease having a higher incidence of appendix cystadenomas, ${ }^{[12]}$ and bariatric patients having a higher incidence of appendix carcinoid tumours. ${ }^{[13]}$ It is felt that screening is not warranted considering the low incidence of these types of tumours.

\section{Conclusions}

Regardless of histological sub-type, no clear screening guidelines for family members of patients with epithelial appendix tumours are available. Families experiencing appendiceal tumours in more than one family member do not require rare hereditary predisposition to be ruled out. If clinical concern of worry from families occurs screening could be performed with a combination of imaging and serum tumour markers. This would be likely to identify similar disease in other family members. Specialist centres should guide the timing and frequency of these investigations with experience in treat- 
ing primary appendiceal epithelial malignancies. We do not recommend prophylactic removal of the appendix however further research into this area is needed.

\section{CONFLICTS OF INTEREST DisClOSURE}

The authors declare they have no conflicts of interest.

\section{REFERENCES}

[1] Li C, Kanthan R, Kanthan SC. Pseudomyxoma peritonei-a revisit: report of 2 cases and literature review. World Journal of Surgical Oncology. 2006; 4(1): 1-6. PMid: 16393338. http://dx.doi.org /10.1186/1477-7819-4-1

[2] Racek AR, Rabe KG, Wick MJ, et al. Primary appendiceal mucinous adenocarcinoma in two first-degree relatives: case report and review. Hereditary Cancer in Clinical Practice. 2011; 9(1): 1-4. PMid: 21542938. http://dx.doi.org/10.1186/1897-4287-9-1

[3] Mcgory ML, Maggard MA, Kang H, et al. Malignancies of the appendix: beyond case series reports. Diseases of the Colon \& Rectum. 2005; 48(12): 2264-71. PMid: 16258711. http://dx.doi.org/1 $0.1007 / \mathrm{s} 10350-005-0196-4$

[4] Smeenk RM, van Velthuysen ML, Verwaal VJ, et al. Appendiceal neoplasms and pseudomyxoma peritonei: a population based study. European Journal of Surgical Oncology. 2008; 34(2): 196-201. PMid: 17524597. http://dx.doi.org/10.1016/j.ejso. 2007 .04 .002

[5] Anderson RE. A Familial Instance of Appendiceal Carcinoid. American Journal of Surgery. 1966; 111(5): 738-740. http://dx.doi.o $\mathrm{rg} / 10.1016 / 0002-9610$ (66) 90053-5

[6] Shih IM, Yan H, Speyrer D, et al. Molecular genetic analysis of appendiceal mucinous adenomas in identical twins, including one with pseudomyxoma peritonei. American Journal of Surgical Pathology. 2001; 25(8): 1095-9. PMid: 11474297. http://dx.doi.org/10. 1097/00000478-200108000-00017

[7] Sugarbaker PM, Deraco M, Glehen O, et al. Cytoreductive Surgery $\&$ Perioperative Chemotherapy for Peritoneal Surface Malignancy. Woodbury, CT: Cine-Med; 2013. 1(3): 57-62, 74 p.
[8] Wagner PL, Austin F, Sathaiah M, et al. Significance of Serum Tumor Marker Levels in Peritoneal Carcinomatosis of Appendiceal Origin. Annals of Surgical Oncology. 2013; 20(2): 506-514 PMid: 22941175. http://dx.doi.org/10.1245/s10434-012 $-2627-5$

[9] Ozakyol AH, Saricam T, Kabukcuoglu S, et al. Primary appendiceal adenocarcinoma. American Journal of Clinical Oncology. 1998; 22(5): 458-459. http://dx.doi.org/10.1097/00000421-199 910000-00007

[10] Hara K, Saito T, Hayashi T, et al. A mutation spectrum that includes GNAS, KRAS and TP53 may be shared by mucinous neoplasms of the appendix. Pathology - Research and Practice. 2015; 211(9): 657-664. PMid: 26160192. http://dx.doi.org/10.1016/j.p rp. 2015.06.004

[11] Alakus H, Babicky ML, Ghosh P, et al. Genome-wide mutational landscape of mucinous carcinomatosis peritonei of appendiceal origin. Genome Medicine. 2014; 6(5): 1-11. PMid: 24944587. http://dx.doi.org/10.1186/gm559

[12] Lurmag O, Trindade AJ, Jean L, et al. Appendiceal mucinous cystadenoma is a neoplastic complication of IBD: Case-control study of primary appendiceal neoplasms. Inflammatory Bowel Diseases. 2009; 15(3): 415-421. PMid: 18989894. http://dx.doi.org/10. 1002/ibd. 20764

[13] Crea N, Pata G, Di BE, et al. High incidence of appendix carcinoid tumors among candidates for bariatric surgery: diagnostic and therapeutic implications. Obesity Surgery. 2011; 21(2): 151-156. PMid: 20186577. http://dx.doi.org/10.1007/s11695-010 $-0112-4$ 